\title{
ATOS DE

ISSN: 1809-0354

\author{
AFINIDADES (S)ELETIVAS EM CARTAS: INTERLOCUÇÕES ENTRE RAUL \\ RODRIGUES GOMES E FERNANDO DE AZEVEDO (1932-1973)
}

\author{
(S)ELECTIVE AFFINITIES: INTERLOCUTIONS BETWEEN RAUL RODRIGUES \\ GOMES AND FERNANDO DE AZEVEDO (1932-1973)
}

\section{AFINIDADES (S)ELECTIVAS EN CARTAS: INTERLOCACIONES ENTRE RAUL RODRIGUES GOMES Y FERNANDO DE AZEVEDO (1932-1973)}

\author{
GOES DENARDI, Vanessa \\ goes_vanessa@hotmail.com \\ Universidade Federal de Santa Catarina - UFSC \\ http://orcid.org/0000-0003-3619-4444
}

TEIVE, Gladys Mary Ghizoni gladysteive@gmail.com Universidade do Estado de Santa Catarina - UDESC http://orcid.org/0000-0002-1599-1543

RESUMO Este artigo refere-se à análise das interlocuções, através de correspondências, entre Raul Rodrigues Gomes e Fernando de Azevedo, ambos considerados expoentes na História da Educação brasileira, principalmente por seu protagonismo no que se refere ao período da Escola Nova. Como embasamento teórico-metodológico, optou-se pelo conceito de representação do historiador francês Roger Chartier $(1991,2002,2011)$ e pelos estudos epistolares que compõem a obra de Bastos, Cunha e Mignot (2002). Este trabalho bibliográfico, portanto, nos permite inferir que as 23 cartas de autoria de Raul Gomes e Fernando de Azevedo trazem à tona as afinidades que os unia, bem como as memórias do período em que se pensava um projeto de transformação para a sociedade brasileira, incluindo a escola laica, gratuita e universal.

Palavras-chave: Cartas. Escola Nova. Fernando de Azevedo. Raul Gomes.

ABSTRACT This article refers to the analysis of the correspondence between Raul Rodrigues Gomes and Fernando de Azevedo, both considered exponents in the history of Brazilian education, mainly due to its prominence in the period of the New School. As a theoretical-methodological basis, the concept of representation of the French historian Roger Chartier (1991, 2002, 2011) and the epistolary studies that compose the work of Bastos, Cunha and Mignot (2002) were chosen. This bibliographic work, therefore, allows us to infer that the 23 letters of authorship of Raul Gomes and Fernando de Azevedo bring to light the affinities that united them, 


\section{ATOS DE

as well as the memories of the period in which a project of transformation for Brazilian society was thought, including the secular, free and universal school.

Keywords: Fernando de Azevedo. Letters. New School. Raul Gomes.

RESUMEN Este artículo se refiere al análisis de las interlocuciones, a través de correspondencias, entre Raul Rodrigues Gomes y Fernando de Azevedo, ambos considerados exponentes en la historia de la educación brasileña, principalmente por su protagonismo en lo que se refiere al período de la Escuela Nova. Como base teórica y metodológica, se utilizó el concepto de representación del historiador francés Roger Chartier $(1991,2002,2011)$ y los estudios epistolares que componen la obra de Bastos, Cunha y Mignot (2002). Este trabajo bibliográfico, por lo tanto, nos permite inferir que las 23 cartas de autoría de Raul Gomes y Fernando de Azevedo traen a la luz las afinidades que los unía, así como las memorias del período en que se pensaba un proyecto de transformación para la sociedad brasileña, incluyendo la escuela laica, gratuita y universal.

Palabras clave: Escuela Nueva. Fernando de Azevedo. Raul Gomes.

\section{INTRODUÇÃO}

Verba volant, scripta manent ${ }^{1}$.

Em nossa vida, nunca dispensamos histórias e é certo que não existe povo sem narrativa. Quem nunca precisou de uma boa história para descobrir, sonhar, sorrir, conhecer melhor o mundo ou as pessoas? Dessa forma, a narrativa passou a exercer um papel de extrema importância nas diversas circunstâncias da vida, o que acabou gerando vários modos de contar uma história e, consequentemente, diversos tipos de diegeses e gêneros textuais, como é o caso das cartas. Narrada em primeira pessoa, a correspondência é a encarnação material das relações pessoais, além de um potencial fonte de informação histórica. "As cartas constituemse em documentos que permitem compreender itinerários pessoais e profissionais de formação, seguir a trama de afinidades eletivas e penetrar em intimidades alheias" (MIGNOT, 2002, p. 116).

Segundo Douphin e Poublan (2002), as cartas ocupam, tradicionalmente, dentro da historiografia, o status de documento, pois as peculiaridades do remetente, do destinatário e até mesmo das pessoas citadas, valorizam o conteúdo

\footnotetext{
${ }^{1}$ Provérbio utilizado por antigos romanos que significa "As palavras voam, os escritos permanecem".
} 


\section{ATOS DE

da missiva. Além disso, as frases, sejam elas simples ou rebuscadas, podem ser consideradas signos ou indícios a serem interpretados.

Como qualquer outra fonte para o historiador, a correspondência é um objeto construído, inscrito no tempo e no espaço social, desde a origem, uma a uma, cartas esparsas, até sua descoberta, quando reunidas em um todo indissociável. Este processo de construção de uma correspondência se mantém nos gestos de destruição (cartas queimadas ou jogadas), na erosão do tempo (cartas perdidas ou esquecidas) quanto às intervenções sucessivas para conservar os "papéis de família" (DAUPHIN; POUBLAN, 2002, p. 80).

Para a Nova História Cultural, entendido como lugar no qual se articulam práticas e representações, $\mathrm{o}$ ato de escrever cartas é considerado um gesto privilegiado. Roger Chartier (1991) afirma que a epístola associa o lugar social e a subjetividade mantendo a tensão entre o segredo e a sociabilidade, seja ela livre ou codificada, íntima ou pública. Destarte, a correspondência como representação apresenta-se como possibilidade de entendimento social e cultural da realidade através da representação de algo real e permeado de sentido.

É possível, dessa forma, afirmar que o epistolar, como produção discursiva, é complementar à presença e à aparência factual. Para Castillo Gomez (2002, p. 25), as cartas explicitam um duplo ato de representação: por um lado, o da pessoa ausente que se mostra através do signo escrito e do suplemento que acarreta, e, por outro, por sua função como espaço de conhecimento pessoal.

Consoante a esse pensamento, Chartier (2002) atenta para a dupla compreensão do conceito de representação: i) presentificação do ausente, substituindo-Ihe por algo habilitado a restituí-lo em memória, supondo uma clara diferença entre o que representa e o que é representado; e ii) exibição de presença, manifestação pública de coisa ou pessoa. No caso deste artigo, é possível dizer que a representação se deu através dessas duas definições, já que os escritos epistolares ressaltam e projetam ideais intelectuais e pessoais havendo identificação entre o representante e o representado e produzindo uma prática de produção de sentido.

A análise das correspondências como representações, portanto, pode ser entendida como um desafio de realizar uma investigação documental que apresenta vestígios de uma história representada por um objeto, além de admitir o uso do escrito para compreender como os indivíduos em questão constroem 


\section{ATOS DE

representações de seu mundo e permeiam suas percepções e experiências de significações variadas (CHARTIER, 1991).

[...] não existe história possível se não se articulam as representações das práticas e as práticas da representação. Ou seja, qualquer fonte documental que for mobilizada para qualquer tipo de história nunca terá uma relação imediata e transparente com as práticas que designa. Sempre a representação das práticas tem razões, códigos, finalidades e destinatários particulares. Identificá-los é uma condição obrigatória para entender as situações ou práticas que são o objeto da representação (CHARTIER, 2011, p. 16).

Nesse sentido, apesar de saber que as cartas podem parecer fidedignas aos fatos por serem escritas em primeira pessoa, terem caráter íntimo e por conterem um discurso espontâneo não destinado à publicação - o que thes reafirmam a intenção de verdade (BASTOS, 2002) -, é preciso destacar que elas, utilizadas como fontes, não devem ser entendidas como testemunho da realidade, pois "comportam mecanismos de ilusão cujas regras e efeitos são constitutivos de sua significação" (DOUPHIN; POUBLAN, p. 76).

Todavia, Ana Chrystina Mignot (2003) aponta que, para os pesquisadores, e principalmente para os historiadores da educação, as cartas são papeis que possibilitam iluminar a escrita ordinária e, no caso das epístolas de Raul Gomes e Fernando de Azevedo, compreender o contexto histórico e educacional de cada um; por isso a importância do cuidado com o uso (in)devido das fontes.

Expressas em forma de sociabilidade e amistosidade, as correspondências trocadas entre esses dois intelectuais permitem revisitar suas trajetórias e ampliar a compreensão a respeito da história educacional do país, em particular, sobre o papel desempenhado por eles e pelo comprometimento com um projeto de transformação da sociedade brasileira no qual se queria a escola laica, gratuita e universal.

Aqui, intelectual é entendido sob a perspectiva do historiador francês JeanFrançois Sirinelli (2003) como aquele que exerce o papel de mediador cultural quando contribui para a difusão e vulgarização dos conhecimentos de uma criação e de um saber através de um certo engajamento que the legitima ou privilegia diante da causa defendida. Nessa mesma direção, Leal (2003) aponta que os intelectuais brasileiros contextualizados nas primeiras décadas do século XX atuaram a fim de reorganizar o país por meio da promoção de um amplo debate político em torno das 


\section{ATOS DE \\ PESQUISA \\ EM EDUCAÇÃO}

ISSN: 1809-0354

869

questões ligadas à unidade nacional, à modernização e à incorporação de novos setores sociais.

Bastos, Cunha e Mignot (2002) apontam que as cartas incitam um grande interesse nos(as) estudiosos(as) da área da História e Historiografia da Educação, por conterem laços e sinais de um determinado tempo, além de evidenciarem formas próprias e singulares de um relacionamento social. Entretanto, apesar de apresentarem e revelarem expressões de confiança, amizade, imagens de sonhos e até utopias presentes no comando privado de seus autores - compondo um verdadeiro memorial dos protagonistas -, muitas dessas epístolas datadas do século XX ainda não passaram para o domínio público (PIMENTEL, 2003).

De sorte que as correspondências analisadas neste trabalho, num total de 23 e compreendidas entre os anos de 1932 e 1973, podem ser encontradas no acervo de Fernando de Azevedo, disponível para consulta no Instituto de Estudos Brasileiros (IEB-USP). Além disso, há também dois artigos publicados nos jornais curitibanos O Estado e O Dia (1937) que transcrevem bilhetes trocados entre Raul Gomes e Fernando de Azevedo e que serão utilizados aqui para destacar que a amizade entre os dois não ficava apenas no âmbito do privado.

Por isso, através da análise documental e de um referencial teórico alicerçado nos estudos epistolares, este artigo busca compreender nos discursos dos missivistas o contexto em que estavam inseridos e as afinidades que os unia, bem como revisitar as memórias do período em que se pensava um projeto de modernização e de transformação para a sociedade brasileira a partir dos preceitos do movimento escolanovista.

\section{AMICIUS CERTUS IN RE INCERTA CERNITUR²: O CONTEXTO DA AMIZADE ENTRE REMETENTE E DESTINATÁRIO}

Não se sabe ao certo o início da aproximação entre Fernando de Azevedo e Raul Gomes, mas é possível pensar que tenha sido resultado das intervenções durante as Conferências Nacionais de Educação (CNE's) em que ambos estiveram

\footnotetext{
${ }^{2}$ Expressão oriunda do latim que tem por tradução: "o amigo certo se manifesta na ocasião incerta".
} 


\section{ATOS DE \\ PESQUISA \\ EM EDUCAÇÃO}

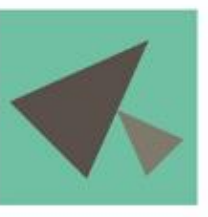

ISSN: 1809-0354

presentes em 1927, 1928 e 1929, já que não constam informações de que tenha havido uma relação pessoal ou profissional entre eles antes desses eventos.

As CNE's foram idealizadas e promovidas pela Associação Brasileira de Educação ( $A B E)$, instituição que contava com a união de intelectuais, como Heitor Lyra da Silva, Everardo Backheuser, Barbosa de Oliveira e Lysímaco da Costa, os quais partilhavam certos princípios nacionalistas em relação ao futuro da educação brasileira e da sociedade moderna. A primeira CNE aconteceu em Curitiba, Paraná, no ano de 1927, na qual Raul Rodrigues Gomes, por ser filho desse Estado, atuou ativamente como proponente de teses que refletiam assuntos sobre a formação de professores e obrigatoriedade escolar. Já Fernando de Azevedo participou como delegado, representando o Estado de São Paulo.

Nas Conferencias Nacionais realizadas em Belo Horizonte e em São Paulo, em 1928 e 1929, respectivamente, ambos tiveram intensa participação, ampliando sua rede de sociabilidade - tanto com seus pares, os chamados Pioneiros da Educação Nova; quanto com seus opositores, os católicos -, e estreitando os laços e ideais que os uniam. Nesse contexto de efervescência escolanovista, os discursos de Raul Gomes e Fernando de Azevedo reconheceram-se e, a partir de então, muitos envelopes começaram a sair da Rua Clotário Portugal, n. 244, em Curitiba, rumo à Rua Bragança, n. 55, em São Paulo, e vice-versa.

Figura 1 - Envelope de carta enviada a Raul Gomes por Fernando de Azevedo (10 de abril de 1969).

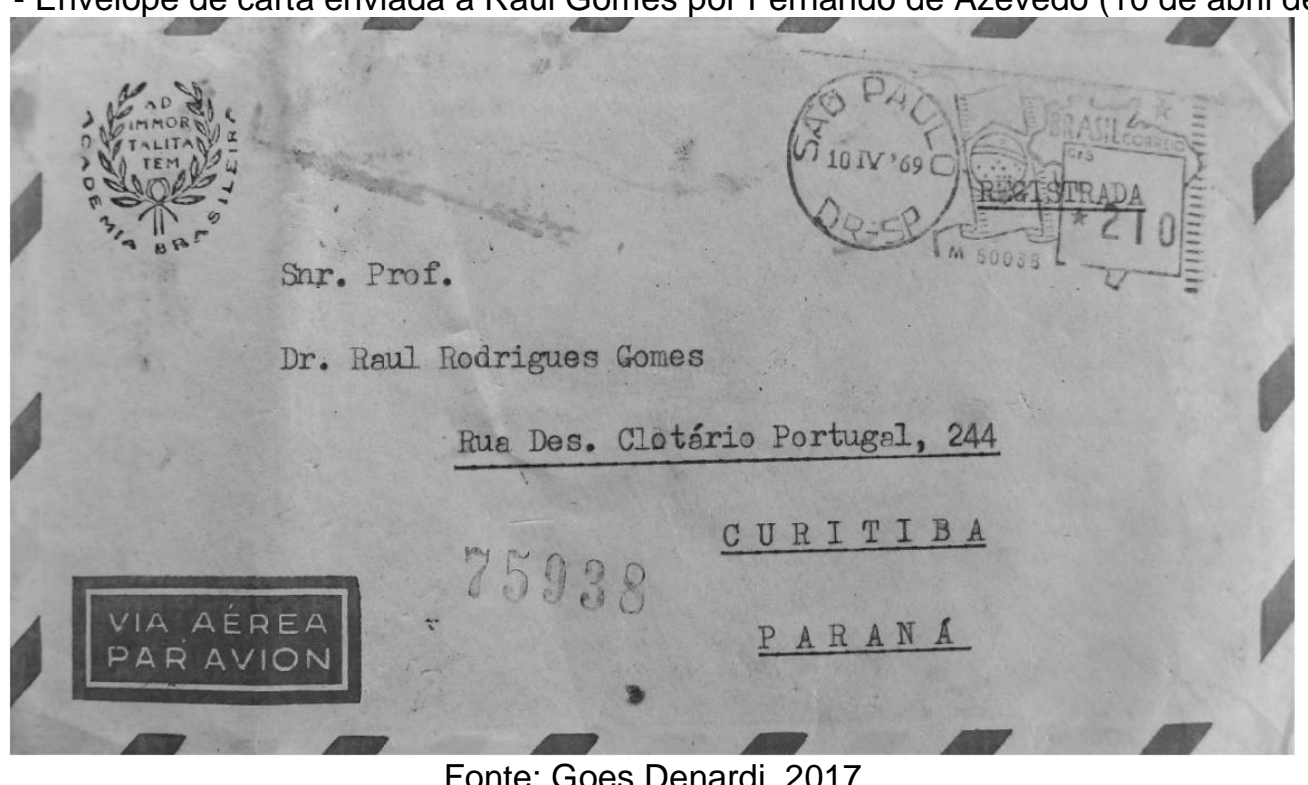




\section{ATOS DE

É possível inferir, portanto, que ambos os intelectuais desenvolveram uma afinidade eletiva ${ }^{3}$, conceito movimentado pelo escritor alemão Johann Wolfgang Von Goethe (1809) que parte de uma apropriação sobre as leis da química para abordar a relação entre os seres humanos a partir de suas afinidades, ou seja, assim como os metais, as pessoas se atraem ou se repelem de acordo com suas preferências. (GOES DENARDI, 2017). Neste caso, também é possível considerar a afinidade eletiva, segundo Pierre Bourdieu (2007, p. 225), como aquela que "baseia-se sempre, por um lado, na decifração inconsciente de traços expressivos em que cada um só adquire sentido e valor no interior do sistema de suas variações segundo as classes".

Daí podemos entender que as afinidades, além de eletivas, podem ser seletivas, pois uma amizade, assim como no caso de Raul Gomes e Fernando de Azevedo, envolve também uma eleição, uma escolha. Nesse caso, ambos escolheram aproximar-se pelas afinidades nas trajetórias pessoais e intelectuais, já que estavam engajados em um campo com o mesmo número de interesses fundamentais em comum ligados à existência própria desse campo (BOURDIEU, 1983), afirmação essa que se torna clara através das cartas trocadas entre eles.

"Lembra você as lutas que travamos e nas quais nunca me faltaram seu apoio e sua solidariedade, quando procurava como no caso dos manifestos, ou quando delas tinha você conhecimento. Não era só um constante testemunho de que amicus certus in re incerta cernitur. $O$ que nos atraís, em momentos difíceis, era a fidelidade aos mesmos propósitos e ideais nas lutas pela educação e cultura (AZEVEDO, 1969b, p. 1)".

O conceito de campo, movimentado por Bourdieu (1983, 1996), é aqui utilizado para caracterizar o âmbito educacional, dentro do qual está inserido o Movimento da Escola Nova, a medida em que esse prevê disputas ideológicas em um campo de forças que coage os agentes nele inseridos, bem como em um campo de lutas, no qual os agentes atuam conforme seus posicionamentos, mantendo ou remodelando sua estrutura.

Para Bourdieu (1983), cada campo tem suas propriedades específicas, como uma espécie de jogo, em que são estabelecidas relações entre participantes/agentes em uma luta de interesses em busca de um monopólio que

\footnotetext{
3 O conceito está presente em: GOETHE, Johann Wolfgang von. As afinidades eletivas. São Paulo:
} Nova Alexandria, 2008. $232 \mathrm{p}$. 


\section{ATOS DE \\ PESQUISA \\ EM EDUCAÇÃO}

ISSN: 1809-0354

872

envolve alianças, rupturas e estratégias. Esses agentes, por não serem sujeitos estáticos, que obedecem a uma estrutura mais global, são habilitados a criar, participar, e, principalmente, a lutar por um capital simbólico que outorga legitimidade, prestígio e autoridade. Assim, todos os agentes da luta contribuem para a reprodução do jogo agregando valor ao que está sendo disputado (GOES DENARDI, 2017). Nesse sentido, é importante saber o posicionamento de Raul Gomes e Fernando de Azevedo dentro do jogo do campo educacional para, então, compreender a escolha de suas concepções e de sua rede de sociabilidades que compactuaram para a conservação da produção desse campo através de seus escritos relacionados a outras obras - passadas ou contemporâneas - sobre a Escola Nova.

Da mesma forma como a personagem Otillie, da obra de Goethe, Raul Gomes e Fernando de Azevedo registraram de forma subjetiva aquilo que estava nas entrelinhas do campo educacional no Brasil, principalmente no que se refere ao Manifesto dos Pioneiros da Escola Nova (1932), fazendo das correspondências pessoais um espaço definidor e definido pela sua sociabilidade (VENÂNCIO, 2002). Mesmo não estando na presença um do outro e por intermédio de um objeto escrito, percebe-se o desenvolvimento de um jogo interativo, indicando o lugar social dos remetentes, suas redes de relações e os interesses em jogo, que neste caso, dá-se no campo da educação.

O Manifesto dos Pioneiros da Escola Nova, redigido por Fernando de Azevedo e lançado em 1932, propunha uma grande mudança, ou, por assim dizer, a reforma das reformas. Situado no contexto da Revolução de 1930, o documento sugeria coordenadas para a organização do ensino e da educação pública, exigindo do Estado uma escola gratuita, obrigatória, laica e em regime de coeducação. $O$ texto repercutiu negativamente entre os educadores católicos que não pouparam críticas às ideias dos pioneiros. A pedido de Fernando de Azevedo, Raul Gomes divulgou entre 29 de março e 07 de abril de 1932 trechos do Manifesto no jornal curitibano Diário da Tarde e, depois disso, passou a publicar artigos defendendo os postulados da Escola Nova.

Nesse sentido, sabendo que um campo só pode funcionar se encontra indivíduos socialmente predispostos a se comportarem como agentes decididos a 


\title{
ATOS DE

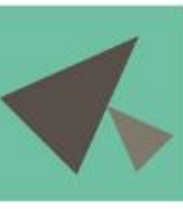

ISSN: 1809-0354

873

arriscarem-se para perseguir os objetivos e obter proveitos decorrentes (BOURDIEU, 1983), Raul Gomes e Fernando de Azevedo buscaram, como pioneiros, promover em seus Estados os preceitos escolanovistas sob a égide de um discurso renovador das escolas do país e, através de cartas, trocaram ideias e experiências, materiais e documentos para fomentar e relembrar esses ideais até as últimas de suas correspondências encontradas.

\begin{abstract}
"Com permissão ou não da excelentíssima senhora D. Ética, pus no endereço a palavra amigo objetivada pelo superlativo caríssimo. A razão desse tratamento é múltipla: um conhecimento pessoal de mais de quarenta anos; a espontaneidade de minhas atitudes junto em acontecimentos importantes de sua atividade pública como diretor de ensino no Rio de Janeiro e, na constância, da revolução de 1930, em sua gestão naquele setor; a minha manifestação irreversível de eu o considerar o maior pedagogista do mundo, etc. E a sua reação diante de expressões admirativas foi tomando feição, a princípio, por certo de tolerância e depois, progressivamente, de correspondência a sentimentos tão puros, altos e duradouros (GOMES, 1973, p. 1)".
\end{abstract}

Logo, é possível afirmar que as cartas não apenas estabelecem relações, mas falam muito sobre o remetente e apontam sempre algo sobre o destinatário, permitindo aquilatar a intensidade do relacionamento entre os missivistas (BASTOS; CUNHA; MIGNOT, 2002), além de mostrar com clareza o contexto histórico-social no qual ambos estavam imersos.

\section{INTERLOCUÇÕES EM CARTAS: AS LINHAS PELO RUÍDO DA REMINGTON}

\begin{abstract}
Escrever cartas exige tempo, reflexão e disciplina, pois é uma forma de compartilhar vivências mais pessoais, íntimas e até mundanas. Escrevemse e mandam-se cartas pelos mais variados motivos: conversar, seduzir, desabafar, agradecer, pedir, segregar, informar, registrar, vender, comprar, desculpar e desculpar-se, falar da vida, enfim! As cartas seguem um protocolo, obedecem a um outro ritmo de tempo: levam tempo para chegar, muitas vezes demoram para ser respondidas e, não raro, demoram para retornar (BASTOS; CUNHA; MIGNOT, 2002, p. 5).
\end{abstract}

Escritas na antiga máquina datilográfica Remington, as palavras de Raul Gomes e Fernando de Azevedo transmitem para o papel a amizade e as memórias intelectuais de mais de 40 anos de convivência e afinidades, além de trazerem nas entrelinhas dessa história os feitos, as obras e os personagens importantes para a constituição do Manifesto dos Pioneiros da Educação Nova (1932) e de uma mentalidade moderna para a sociedade brasileira. 


\section{ATOS DE

"Passei o mês de fevereiro e o de março às voltas com "MEU GOETHE". E por via de Goethe com os seus contemporâneos ou prediletos. Convive, portanto, com Locke, Rousseau, Pestalozzi, João Paulo, Fitche, Schiller, etc. Quando recebi seu manifesto, eu tinha relido de fresco os Discursos à Nação Alemã". E escrevera alguns tópicos sobre Goethe e Fitche, estes e a educação. Estava, portanto, preparado para a leitura de seu maravilhoso manifesto. Ainda assim fiquei muito comovido. Porque eu esperava "UM MANIFESTO" à nação brasileira há muito tempo (GOMES, 1932a, p. 1, grifos do autor)".

Autodenominado soldado da educação, Raul Gomes deixou claro em diversas correspondências que estava às ordens de seus generais - os quais, supõem-se, serem Fernando de Azevedo, Anísio Teixeira e Lourenço Filho, considerados os cardeais do movimento escolanovista brasileiro - e que se preciso fosse, lutaria nas trincheiras educacionais. Dito e feito. Em abril de 1932, publicou o Manifesto dos Pioneiros da Educação Nova no jornal de maior circulação de Curitiba, o "Diário da Tarde", conforme promessa realizada ao amigo e redator do documento.

Cabe ressaltar que, dentre os educadores de maior ou igual importância no Estado do Paraná, Raul Gomes foi o único paranaense a assinar o Manifesto dos Pioneiros dentre os 26 signatários, quais sejam: Fernando de Azevedo, Afrânio Peixoto, Anísio Teixeira, Lourenço Filho, Roquette Pinto, J.G. Frota Pessoa, Julio de Mesquita Filho, Raul Briquet, Mario Casassanta, C. Delegado de Carvalho, A. Ferreira de Almeira Jr., J.P. Fontenelle, Roldão Lopes de Barros, Noemy M. da Silveira, Hermes Lima, Attilio Vivacqua, Francisco Venancio Filho, Paulo Maranhão, Cecilia Meirelles, Edgar Sussekind de Mendonça, Armanda Alvaro Alberto, Garcia de Rezende, Raul Gomes, Nobrega da Cunha e Paschoal Lemme.

Em missiva datada de 23 de junho de 1932, Raul Gomes enviou uma breve biografia para acompanhar sua assinatura no Manifesto e, com certa modéstia, afirmou que estava "no meio da viagem", que seus desejos pairavam distantes ainda, proclamando-se "obscuro signatário do brilhante manifesto". Na mesma carta, pediu desculpas a Fernando de Azevedo pelo atraso de suas respostas e justificouse apresentando um nome que, futuramente, seria exaltado na educação paranaense: Erasmo Pilotto.

\footnotetext{
"Tenho à vista duas cartas, uma delas salientando que a outra estava sem resposta. SobraIhes razão. E ainda uma vez, enfrento o preceito que diz ser o recebimento de uma missiva um prazer e o responder uma obrigação. E para o cumprimento desta não valem escusas, pois força arranjar na sequência da máxima atividade minutos para executá-la pontualmente. Mas meu caso é sério. E me escoro nele para declarar que, embora viva seu nome na minha lembrança e nas minhas preocupações e confabulações diárias, não pude com a devida presteza acusar a recepção de suas letras amáveis e bondosas, saturadas do perfume de
} 


\section{ATOS DE

doce simpatia que é o meu orgulho e o meu enlevo. O Erasmo veio passas as férias em Curitiba. E, sedento sempre de leituras, gasta a tarde inteira entre meus livros sobre educação (meia dúzia de obras). E nalguns vagares, palestramos. E sua luminosa pessoa, que concentra as mais caras e mais altas esperanças de nós todos para bem e grandeza do Brasil, forma de continuo o objeto de nossas permutas de ideias (GOMES, 1932b, f. 1)".

No ano seguinte, ainda entusiasmado com os preceitos escolanovistas e a repercussão do Manifesto, Raul Gomes exaltou Fernando de Azevedo e entendeu seus escritos como uma diretriz educacional profunda e nova que tinham a predominância da pedagogia social escolar encontrada nos conceitos de Dewey, Nartop, Gasset e Durkheim.

\footnotetext{
"Você, meu ilustre amigo, é fantástico. E cada vez mais você mesmo e mais singular na maneira de solucionar ou atacar a gravíssima questão educacional. Eu mesmo esperava um regulamento. E você me sai com um código. Todos contavam na certa com uma inovação inspirada em escola ativa. E você alça voo, realiza prodigiosos remígios. Divisa de cima assunto, através de sua filosofia pedagógica. E nos dá, por certo não perfeito, mais extraordinário esse código (GOMES, 1933a, p. 1)".
}

A admiração de Raul Gomes por Fernando de Azevedo era tanta que em artigo publicado no Jornal O Dia em 01 de janeiro de 1933, apropriou-se do termo "Ecce Homo" para qualificá-lo como o homem que surgira para dar novos rumos à educação brasileira (GOMES, 1933b). Segundo o Evangelho, Ecce Homo, advindo do latim, foi proferido pelo governador romano Pôncio Pilatos ao apresentar Jesus à multidão que, hostil, pedia sua crucificação. As palavras também foram apropriadas por Friedrich Nietzsche, em 1908, para intitular a obra autobiográfica em que exalta seus feitos e apresenta um novo ideal humano. Posteriormente, também utilizou a expressão em uma de suas cartas:

"Eis o homem, Brasil. É a exclamação que eu poderia atirar aos quadrantes de nossa pátria para denunciar a existência daquele há tanto tempo esperado para efetuar a grande obra educacional que redimira o Brasil de sua vergonhosa situação de cafraria do ensino no cotejo com os demais países do mundo! (GOMES, 1933a, p.1)".

A relação amistosa entre o paranaense e o paulista, rendeu, além de cartas, trocas de livros e a insistência de pareceres sobre os mesmos. Ao enviar a obra "A educação e seus problemas" (1937), Fernando de Azevedo anexou o seguinte bilhete: "Ao R.G. - trabalhador infatigável, cuja solidariedade é um conforto e um estímulo nas lutas comuns pela educação e pela cultura no Brasil, com a afetuosa estima e velha admiração de Fernando de Azevedo." (AZEVEDO, 1937, apud GOMES, 1937, p. 2). 


\title{
ATOS DE

Como forma de agradecimento e lisonjeio, Raul Gomes publicou no jornal $O$ Estado a resposta ao amigo:

\begin{abstract}
"Escrevendo essas linhas, pressentia que, afinal, ellas posteriormente poderiam prejudicar os meus conceitos acerca da obra de Fernando de Azevedo, si ambos necessitassem de qualquer preconício. Ambos dispensam quaisquer elogios. Elle por ser um nome não apenas nacional mas mundial, como autor e realizador de profunda obra educativa em seu Estado e do Rio de Janeiro. Ella pela sua successividade, pela sua unidade e pelo profundo sentido technico cultural. O volume que tenho á vista é formado ele pouco mais de conferências e entrevistas sobre o palpitante assumpto. E em cada um desses trabalhos o autor expõe e defende com lucidez e cultura os mais inteligentes pontos de vistas. Escriptor de raça, com mentalidade e estylo formados á luz de um humanismo ductil e profundo, ha um encanto em cada pagina sua, pois nesta o thema se nos depara liberto de massudez. Cogita-se, portanto de um livro que nenhum educador pode dispensar tão valioso e actual é elle (GOMES, 1937, p. 2)".
\end{abstract}

Meses depois, Fernando de Azevedo retribuiu o apreço, parabenizando Raul pelo segundo volume do livro Prática de Redação, que fora publicado em 1937 pela Editora Nacional, por aquele dirigida:

\begin{abstract}
"Felicitando-o pela excelente série que nos vai dar e que constitue, de fato, a iniciativa mais seria sobre o assunto, em nossa literatura didática, e uma forte contribuição original para renovação e eficiencia maior dos cursos de redação, peço-lhe aceitar os meus agradecimentos pela homenagem que quis prestar a sua generosa amizade incluindo meu nome entre aqueles a quem dedica o seu livro de mestre. Sobre ser uma honra para mim, é um real prazer ter meu nome ligado aos de tão ilustre educadores na pagina que nos reservou o mestre, três vezes consagrado no magisterio, no jornalismo e nas lutas pela educação no Brasil. Um afetuoso abraço de seu sempre Fernando de Azevedo (AZEVEDO, 1937, p. 2)".
\end{abstract}

A homenagem a que se referia Fernando de Azevedo trata-se da dedicatória presente no referido livro de Raul Gomes, na qual também constam os nomes de Anísio Teixeira e Lourenço Filho, além do professor paranaense e amigo Francisco R. de Azevedo Macedo. Em carta datada de 20 de junho de 1959, Raul Gomes evidenciou que de todos os memoráveis educadores da década de 1920, foi com essa tríade que manteve estreita relação sob o ponto de vista pragmático da educação, seguindo os passos de Fernando de Azevedo através de suas realizações, antes e depois do Manifesto dos Pioneiros, e mantendo laços de amizade durante 30 anos com Lourenço Filho e Anísio Teixeira, posicionando-se a favor desse, com coragem e desassombro, na campanha para destituí-lo do cargo de Secretário da Instrução Pública do Distrito Federal em 1935 (GOMES, 1959). Nesse sentido, é possível observar que as redes de sociabilidades permitem criar 


\section{ATOS DE \\ PESQUISA \\ EM EDUCAÇÃO}

ISSN: 1809-0354

877

relações estruturadas em rede que falam de lugares mais ou menos formais de aprendizagem e de troca, de laços que se atam, de contatos e articulações fundamentais... a noção de rede remete ao microcosmo particular de um grupo, no qual se estabelece vínculos afetivos e se produz uma sensibilidade que se constitui marca desse grupo (SIRINELLI, 2003, p. 38).

Na mesma correspondência, Raul Gomes questionou Fernando de Azevedo sobre um possível novo Manifesto que deveria receber assinaturas dos educadores ainda vivos que figuraram no primeiro, e de novos educadores engajados pelos preceitos da Escola Nova, principalmente no que se referia às questões da laicidade e gratuidade do ensino, ideia que foi publicada pelo jornal O Estado de São Paulo, em 20 de junho de 1959, como é possível constatar no excerto abaixo:

A oportunidade de lançamento de um novo manifesto de educadores surgiu da necessidade de se configurar com maiores precisão e objetividade a situação atual e os princípios e tendências da educação no Brasil em face dos debates suscitados pela tramitação na Câmara Federal, do projeto de lei que fixa as diretrizes e as bases da educação nacional e pela apresentação de um substantivo a esse documento legal (O ESTADO DE SÃO PAULO, 1959, p. 11).

Não sendo possível encontrar a resposta enviada por Fernando de Azevedo, mas valendo-se dos vestígios históricos da época, constata-se que o fato realmente ocorreu e, em 01 de julho de 1959, foi publicada a reafirmação do Manifesto com o título Mais uma vez convocados, contando com 161 assinaturas de educadores, dentre eles Raul Gomes. Esse documento, novamente redigido por Fernando de Azevedo, resgatava os ideais liberais do primeiro e reiterava o posicionamento contra o discurso da Igreja Católica fazendo uso das palavras do dominicano Père J. Henri Didon ao afirmar que

"chegou a hora talvez em que o Catolicismo deve demonstrar por fatos públicos que sua larga ideia de universalidade não é uma palavra vã e que há nele lugar para todas as opiniões políticas desde que elas respeitem a verdade, a justiça e a virtude (DIDON, 1880, apud AZEVEDO et al., 2010, p. 80)".

Além das inferências aos Manifestos de 1932 e 1959 na maioria das cartas, Raul Gomes descreveu ao amigo suas ações na luta contra o analfabetismo, sob o viés da obrigatoriedade escolar, com a criação da Operação Paraná de Liquidação do Analfabetismo (OPALA). Compulsoriamente aposentado, o paranaense passou a dedicar-se quase que exclusivamente à erradicação desse mal. Por esse motivo, durante as suas missões para percorrer o Estado na luta pela educação, as cartas 


\title{
ATOS DE

ficaram cada vez mais espaçadas, assim como os artigos destinados aos jornais paranaenses, sendo motivo de desculpas: "Sigo sua vida intelectual com muito interesse. E muitas vezes esqueço, digo, muitas vezes ocorre-me the escrever. Mas minhas complexas preocupações e ocupações me impedem. Pois minha atividade social é grande [...]". (GOMES, 1963, p. 1).

Algumas cartas trocadas por Raul Gomes e Fernando de Azevedo foram enviadas por meio de amigos que transitavam entre as capitais paranaense e paulista - já que por mais de uma vez as correspondências foram extraviadas pelos Correios - bem como livros com que se presenteavam: Máscaras e Retratos (1962), Discursos da Academia (1969) e História de minha vida (1973). Dentre esses amigos estava o poeta e jornalista Cassiano Ricardo e o educador paranaense e criador do Centro Cultural Euclides da Cunha, Faris Antonio Michaele.

As três missivas datadas nos anos de 1967 e $1968^{4}$ são breves e revisitam memórias dos acontecimentos de 1932, muito particularmente na ocasião do Manifesto. Também abordam as homenagens do jornal $A$ Gazeta do Povo à Raul pelos 50 anos de magistério e a eleição de Fernando à Academia Brasileira de Letras $(A B L)$.

"Participe humilde e obscuro da campanha pelo seu ingresso na academia brasileira de letras, tive a meu cargo a propaganda pela imprensa e por cartas e mensagens a acadêmicos de São Paulo e da ABL, senti-me feliz ao constar sua vitória embora ela tardasse, pois dentro desse sodalício deverá estar há muito. (GOMES, 1968, f. 1)".

\begin{abstract}
"Meu caro colega e amigo, que belas e calorosas palavras as que Ihe inspirou sua velha amizade, ao felicitar-me por minha posse na Academia Brasileira. Fico-Ihe tão obrigado por elas quanto agradecido pelo vivo interesse com que acompanhou minha eleição para a Academia. Já antes de 1932, quando me deu a honra de assinar o manifesto dos Pioneiros da Educação nova, sentia a solidariedade e o apoio que me dava em minhas lutas pela educação nacional. E daí por diante eu o tive presente sempre, em espirito e pelo coração, ligados como estávamos por ideias comuns (AZEVEDO, 1968, f. 1)".
\end{abstract}

Em 19 de janeiro de 1969, o jornal O Estado de São Paulo publicou uma mensagem de Fernando de Azevedo intitulada Carta aos jovens, que tratava de questões sociais e da necessidade de mudança para a construção de um país mais justo. Encantado com o texto, Raul Gomes escreveu nos periódicos Diário do Paraná e Gazeta do Povo uma evocação ao mestre paulista abordando seu brilhantismo como um dos maiores psicopedagogistas da época.

\footnotetext{
${ }^{4}$ Duas correspondências de Fernando de Azevedo datadas de 22 de outubro de 1967 e 12 de outubro de 1968, e uma de Raul Gomes escrita em 07 de outubro de 1968.
} 


\section{ATOS DE PESQUISA EM EDUCAÇÃO}

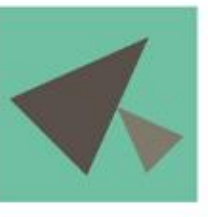

ISSN: 1809-0354

Figura 2 - Artigo de Raul Gomes sobre "Carta aos jovens"

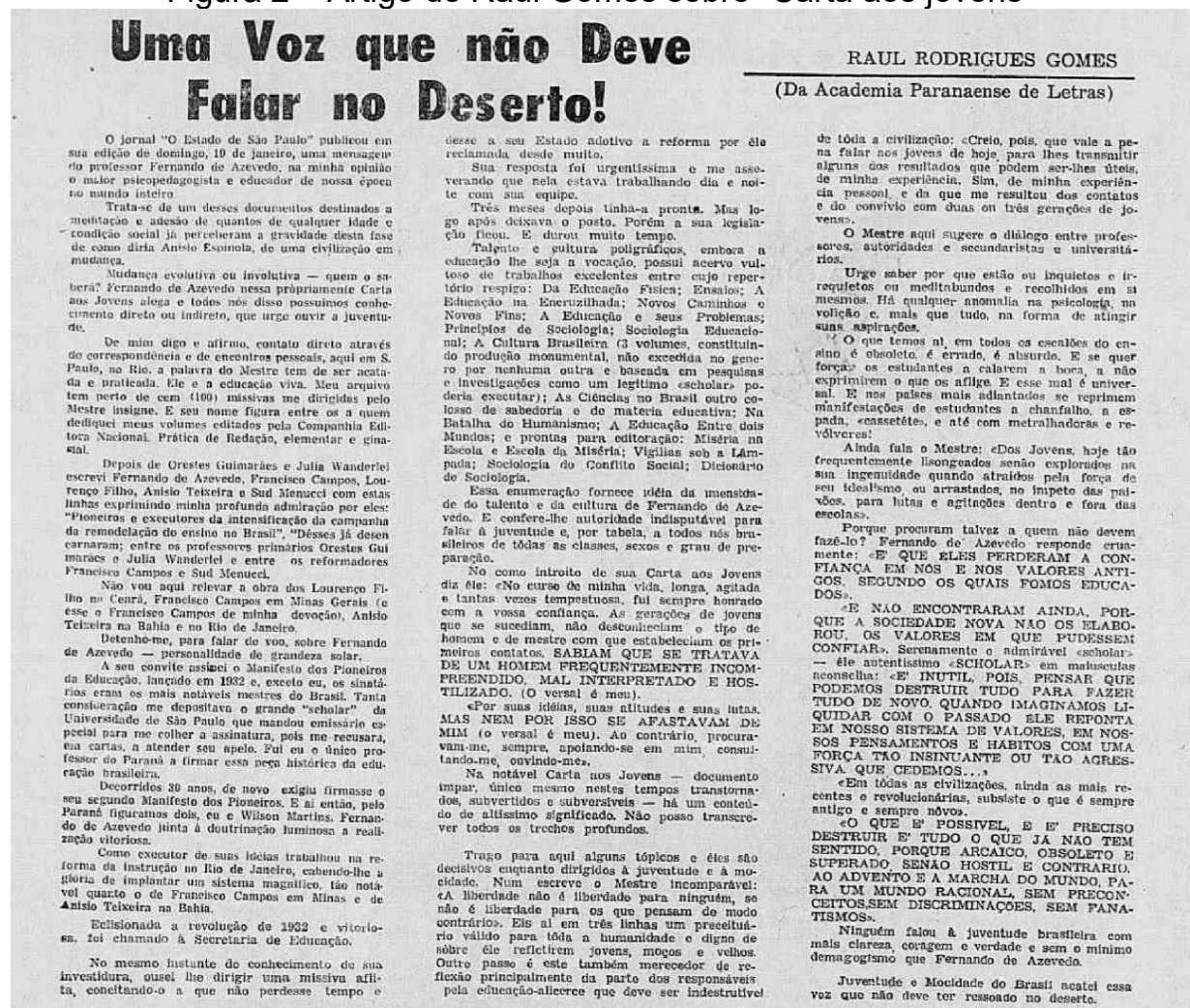

Fonte: Diário do Paraná (GOMES, 1969, p. 2).

Ao ler a homenagem feita pelo amigo, Fernando de Azevedo enviou uma carta agradecendo as generosas palavras com as quais foram referidos seu nome e suas obras: "De tantas e tão calorosas manifestações de solidariedade e apoio, a sua (creia-me) foi uma das que mais me tocaram o coração. (...) E que belos artigos Ihe inspirou, em sua benevolência comigo, a leitura de minha Carta aos Jovens" (AZEVEDO, 1969a, p. 1).

Uma mescla de admiração e devoção é evidente em todos os escritos de Raul em relação a Fenando de Azevedo, um culto que leva à perplexidade e ao reconhecimento de qualidades que chegam, inclusive, a ser magnificadas. Esta carta traduz o sentimento de Raul Gomes para com o amigo, no qual sempre buscou espelhar-se pelo caráter, personalidade e forma de encarar os problemas da educação:

"Fernando de Azevedo, significa para mim, para todos os professores do Brasil, a maior capacidade produtiva e educador. Assim, fiquei sabendo de sua atividade, como sempre valiosa, senão essencial para a nossa evolução. Eu não me iludo: nem me empreciono com a 


\title{
ATOS DE

barulheira em torno de reformas idealizadas, "inventadas", por quem entende tanto de organização fundamental do ensino e da cultura quanto eu de sanscrito. Na minha longa vida de lutador apagado e modesto pela fomação do povo brasileiro, só conheci 3 possantes e eluminadas personalidades com competencia e sabedoria cultural e tecno-logicas, aqui mencionadas, ainda assim na ordem de sua possibilidade em teoria, doutrina, pragmatismo e realização. Primeira: Fernando de Azevedo; segunda: Anizio Teixeira; terceira: Manoel Lourenço Filho. Fora dessa triade só sobre-vive, pelo bem do Brasil a meu caro e brilhante amigo. É de ver, portanto, o jubelo sentido por mim quando leio informação objetiva de sua presença nas trincheiras desenvolvendo suas produtividades insuperaveis pela grandeza de nossa Patria (GOMES, 1972, f. 1)".

Em 1972 e 1973, ambos ainda estavam ativos em prol da educação, apesar da idade avançada e dos problemas de visão de Raul. "Meu caro amigo, se me entristeceu saber, por sua carta, de uma deficiencia de visão, alegrou-me referir-se você aos seus 'sólidos 84 anos'. Antes de atingir os meus oitenta, já se me vai apagando, e rapidamente, a luz dos olhos" (AZEVEDO, 1973, p. 1). Porém, isso não Ihes impediu de escrever as últimas e amistosas correspondências. Em tempo, na mesma carta do trecho acima, Fernando de Azevedo também lamentou que Anísio Teixeira e Lourenço Filho já tivessem partido e agradeceu o apoio e a amabilidade de sempre do amigo Raul Gomes:

\begin{abstract}
"V. é um dos mais lembrados amigos, - um dos que mais me apoiaram, trazendo-me o conforto da solidariedade e de seus estimulos em minhas lutas. Em meus encontros com amigos e em reuniões nesta sua casa, nunca nos falta sua presença em recordações. Dos três educadores a que $V$. se refere, e dos quatro que eram frequentemente citados juntos, a saber Anisio Teixeira, Lourenço Filho, e eu proprio, acrescidos mais tarde do nome ilustre de nosso inesquecivel A. F. de Almeida Junior, sou eu, eu, o que deveria durar menos o sobrevivente. Ė uma tristeza sobreviver a tantos e tão grandes. Sempre que puder, escrevame, que são para mim, um prazer suas cartas, tão finas, amaveis e cheias de recordações. Dessas lembranças que, na solidão, se tornam mais vivas e não cessam de despertar outras e outras. Se recordar não é viver, como se diz, é certamente reviver, acordar, recordar dias alegres ou tristes, mas intensamente vividos (AZEVEDO, 1973, f. 1)".
\end{abstract}

Menos de um ano após essa missiva, em 18 de setembro de 1974, morria Fernando de Azevedo e, em 12 de novembro de 1975, Raul Rodrigues Gomes, os quais deixaram essas memórias que mapeiam a identidade pioneira e ideal de vida dos dois, bem como, constroem imagens a partir de um discurso calcado em relações de confiança, laços de solidariedade e admiração fraternas, marcadoras de presença e de sonhos, símbolos de uma identidade tecida nas estratégias das lutas cotidianas pelo ensino e pela educação escolar. (PIMENTEL, 2003).

Por fim, vale destacar o tom das despedidas das missivas, já que, ao término, havia sempre um "artefato cultural cuja linguagem e disposição projetam uma determinada imagem da pessoa que escreve" (CASTILLO GOMEZ, 2002, p. 43). 


\section{ATOS DE \\ PESQUISA \\ EM EDUCAÇÃO}

ISSN: 1809-0354

881

Dessa forma, constata-se que nas cartas aqui analisadas o abraço nunca foi esquecido, tampouco a expressão de estima e admiração um pelo outro: "Abraço-o cordialmente e aqui fico como seu fiel admirador, aguardando para mais uma vez subscrever o seu célebre manifesto de 1932' (GOMES, 1968, p. 1).

\section{CONSIDERAÇÕES FINAIS}

Diante dessa significativa troca epistolar, percebe-se que as cartas, como objeto de transmissão, tornam-se elementos chave para a construção de sentido, bem como para a compreensão do contexto e dos grupos aos quais os indivíduos pertencem, representam-se e são representados. Assim, é possível reconhecer a identidade social de cada um dos missivistas e a maneira como remetente e destinatário presentificavam-se.

As correspondências de Raul Gomes e Fernando de Azevedo possuem vestígios da história, sinalizando um momento importante da educação brasileira e os avanços e percalços da luta por uma educação escolar laica, gratuita, universal e em regime de coeducação, preceitos caros ao movimento escolanovista brasileiro e que ambos os intelectuais partilhavam.

Apesar da Escola Nova não ter sido abordada de forma aprofundada no conteúdo das cartas, pode-se inferir que foi por ela que a aproximação dos dois intelectuais aconteceu. É mister destacar ainda que a devoção de Raul Gomes por Fernando de Azevedo, que chegou a considerá-lo seu mestre e guia, dava-se não somente pela amizade que mantinham, mas pela visibilidade e importância que esse intelectual conservava nacional e internacionalmente, bem como por seu engajamento frente às lutas educacionais durante uma vida inteira.

\section{VANESSA GOES DENARDI}

Doutoranda em Linguística pela Universidade Federal de Santa Catarina. Mestra em Educação pela Universidade do Estado de Santa Catarina. Professora da Faculdade Estácio Florianópolis e Centro Universitário Municipal de São José.

\section{GLADYS MARY GHIZONI TEIVE}

Doutora em Educação pela Universidade Federal do Paraná, com Sandwich na área de Currículo na UNED, em Madri/Espanha. Pós-doutora pelo Centro de 


\section{ATOS DE \\ PESQUISA \\ EM EDUCAÇÃO}

ISSN: 1809-0354

882

Investigación em Manuales Escolares-MANES/UNED. Professora titular da Universidade do Estado de Santa Catarina.

\section{REFERÊNCIAS}

AZEVEDO, F. [Carta] 8 ago. 1937, São Paulo [para] GOMES, Raul Rodrigues, Curitiba. In: Academia Paranaense de Letras. O Estado, Curitiba, 19 de ago. 1937, p. 2.

AZEVEDO, F. [Carta] 22 out. 1967, São Paulo [para] GOMES, Raul Rodrigues, Curitiba. 1f. Acervo Fernando de Azevedo - IEB/USP: FA-CA_CX7,35.

AZEVEDO, F. [Carta] 12 out. 1968, São Paulo [para] GOMES, R. R., Curitiba. 1 f. Acervo Fernando de Azevedo - IEB/USP: FA-CA_CX7,36.

AZEVEDO, F. [Carta] 28 fev. 1969a, São Paulo [para] GOMES, R. R., Curitiba. 1 f. Acervo Fernando de Azevedo - IEB/USP: FA-CA_CX7,37.

AZEVEDO, F. [Carta] 05 abr. 1969b, São Paulo [para] GOMES, R. R., Curitiba. 1f. Acervo Fernando de Azevedo - IEB/USP: FA-CA_CX7,39.

AZEVEDO, F. [Carta] 25 mai. 1973, São Paulo [lpara] GOMES, R. R., Curitiba. 1 f. Acervo Fernando de Azevedo - IEB/USP: FA-CA-Cx7,41.

AZEVEDO, F. et al. Manifesto dos pioneiros da Educação Nova (1932) e dos educadores (1959). Recife: Fundação Joaquim Nabuco, Editora Massangana, 2010. Disponível em: http://www.dominiopublico.gov.br/download/texto/me4707.pdf. Acesso em: 16 mar. 2019.

BASTOS, M. H.; CUNHA, M. T. S.; MIGNOT, A. C. V. Laços de Papel. In: BASTOS, M.H; CUNHA, M.T.S; MIGNOT, A.C.V. (org.). Destino das letras: história, educação e escrita epistolar. Passo Fundo (RS): Editora da UPF, 2002, p. 05-09.

BASTOS, M.H.C. De pai para filha: cartas sobre a educação de Cora (1849). In: BASTOS, M.H; CUNHA, M.T.S; MIGNOT, A.C.V. (org.). Destinos das Letras: história, educação e escrita epistolar. Passo Fundo: UPF, 2002, p. 89-113.

BOURDIEU, P. Questões de Sociologia. Rio de Janeiro: Marco Zero, 1983.

BOURDIEU, P. Razões práticas: sobre a teoria da ação. São Paulo: Papirus, 1996.

BOURDIEU, P. A Distinção: crítica social do julgamento. São Paulo/Porto Alegre: EDUSP/Zouk, 2007.

CASTILLO GOMEZ, A. Como o polvo e o camaleão se transformam: modelos e práticas epistolares na Espanha moderna. In: BASTOS, M.H; CUNHA, M.T.S; 


\section{ATOS DE \\ PESQUISA \\ EM EDUCAÇÃO}

ISSN: 1809-0354

MIGNOT, A.C.V. (org.). Destinos das letras: história, educação e escrita epistolar. Passo Fundo: UPF, 2002. p. 13-55.

CHARTIER, R. La Correspondance. Les usages de la lettre au XIX siècle. Paris: Fayard, 1991.

CHARTIER, R. À beira da falésia: a história entre certezas e inquietude. Porto Alegre: Ed. da UFRGS, 2002.

CHARTIER, R. Defesa e ilustração da noção de representação. Fronteiras, Dourados, MS, v. 13, n. 24, p. 15-29, jul./dez. 2011. Disponível em: https://www.ufrgs.br/gthistoriaculturalrs/nocaoderepresentacao.pdf. Acesso em: 29 mar. 2019.

DAUPHIN, C; POUBLAN, D. Maneiras de escrever, maneiras de viver: Cartas familiares no século XIX. In: BASTOS, M.H; CUNHA, M.T.S; MIGNOT, A.C.V. (org.). Destinos das Letras: história, educação e escrita epistolar. Passo Fundo: UPF, 2002. p. 75-87.

GOES DENARDI, V. Entre teses: uma travessia pelas representações do professor Raul Rodrigues Gomes sobre a Escola Nova (décadas de 1920 e 1930). 2017. (Dissertação) Mestrado em Educação - Universidade do Estado de Santa Catarina, Florianópolis.

GOETHE, J. W. V. As afinidades eletivas. São Paulo: Nova Alexandria, 2008.

GOMES, R. R. [Carta] 03 abr. 1932a, Curitiba [para] AZEVEDO, F., São Paulo. $2 f$. Acervo Fernando de Azevedo - IEB/USP: FA-CP-Cx13,62.

GOMES, R. R. [Carta] 23 jun. 1932b, Curitiba [para] AZEVEDO, F., São Paulo. $3 f$. Acervo Fernando de Azevedo - IEB/USP: FA-CP-Cx13,65.

GOMES, R. R. [Carta] 08 mai. 1933a, Curitiba [para] AZEVEDO, F., São Paulo. 2 f. Acervo Fernando de Azevedo - IEB/USP: FA-CP-Cx13,66.

GOMES, R. R. Ecce Homo!. O Dia, Curitiba, 01 jan. 1933b, p. 2.

GOMES, R. R. Seara Alheia. O Estado, Curitiba, 25 de mai. de 1937, p. 2.

GOMES, R. R. [Carta] 20 jun. 1959, Curitiba [para] AZEVEDO, F., São Paulo. $2 f$. Acervo Fernando de Azevedo - IEB/USP: FA-CP-Cx13,69.

GOMES, R. R. [Carta] 21 fev. 1963, Curitiba [para] AZEVEDO, F., São Paulo. 2 f. Acervo Fernando de Azevedo - IEB/USP: FA-CP-Cx13,71.

GOMES, R. R. [Carta] 07 out. 1968, Curitiba [para] AZEVEDO, F., São Paulo. 1 f. Acervo Fernando de Azevedo - IEB/USP: FA-CP-Cx13,72. 


\section{ATOS DE \\ PESQUISA \\ EM EDUCAÇÃO}

ISSN: 1809-0354

884

GOMES, R. R. Uma voz que não deve falar no deserto. Diário do Paraná, 11 de fevereiro de 1969, p. 2.

GOMES, R. R. [Carta] 18 mai. 1972, Curitiba [para] AZEVEDO, F., São Paulo. 1 f. Acervo Fernando de Azevedo - IEB/USP: FA-CP-Cx13,75.

GOMES, R. R. [Carta] 16 jul. 1973, Curitiba [para] AZEVEDO, F., São Paulo. 1 f. Acervo Fernando de Azevedo - IEB/USP: FA-CP-Cx13,77.

LEAL, M. C. Retratos da educação brasileira: contraste entre a educação republicana imaginada e realizada. In: Leal, M. C.; Pimentel, M. A. L. (org.). História e Memória da Escola Nova. São Paulo: Loyola, 2003.

O ESTADO DE SÃO PAULO. Manifesto de educadores em princípios de julho. 1959. São Paulo, 20 jun., p. 11.

MIGNOT, A. C. V. Artesãos da palavra. Cartas a um prisioneiro político tecem redes de ideias e afetos. In: BASTOS, M.H; CUNHA, M.T.S; MIGNOT, A.C.V. (org.). Destino das letras: história, educação e escrita epistolar. Passo Fundo: UPF. 2002, p. 115-136.

MIGNOT, A. C. V. Papéis guardados. Rio de Janeiro: UERJ, Rede Sirius, 2003.

PIMENTEL, M. A. L. Memória e Interpretação de relatos. In: LEAL, M. C.;

PIMENTEL, M. A. L. (org.). História e Memória da Escola Nova. São Paulo: Edições Loyola, 2003, p. 27-53.

SIRINELLI, F. Os intelectuais. In: REMOND, R. (org.). Por uma nova história política. Rio de Janeiro: Fundação Getúlio Vargas, 2003.

VENÂNCIO, G. Sopros inspiradores: trocas de livros, intercâmbios intelectuais e práticas de correspondência no arquivo privado de Oliveira Vianna. In: BASTOS, M.H; CUNHA, M.T.S; MIGNOT, A.C.V. (org.). Destinos das Letras: história, educação e escrita epistolar. Passo Fundo: UPF, 2002. p. 217-242. 